\title{
FUNGI PADA BATANG POHON Paraserianthes falcataria DAN ASOSIASINYA DENGAN Xystrocera festiva (Coleoptera : Cerambycidae)
}

\author{
Fungi of Paraserianthes falcataria and their Association with Xystrocera festiva \\ (Coleoptera : Cerambycidae) \\ Yunasfi $^{1}$, Soetrisno Hadi ${ }^{2}$, Gayuh Rahayu ${ }^{3}$ dan/and Teguh Santoso ${ }^{4}$ \\ ${ }^{1}$ Departemen Kehutanan, Fakultas Pertanian, Unversitas Sumatera Utara, \\ Jl. Tri Dharma Ujung No. 1 Kampus USU Medan \\ ${ }^{2}$ Departemen Silvikultur, Fakultas Kehutanan, Institut Pertanian Bogor \\ Kampus IPB Darmaga Bogor, Bogor \\ ${ }^{3}$ Departemen Biologi, Fakultas Matematika dan Ilmu Pengetahuan Alam, Institut Pertanian Bogor, \\ Kampus IPB Darmaga \\ ${ }^{4}$ Departemen Proteksi Tanaman, Fakultas Pertanian, Institut Pertanian Bogor, \\ Kampus IPB Darmaga Bogor, Bogor \\ Jl. Lingkar Akademik, Kampus IPB Darmaga Bogor 16680
}

Naskah masuk : 15 Januari 2009; Naskah diterima : 21 Juli 2009

\begin{abstract}
The objectives of this research was to determine the species of fungi developed in the stem of Paraserianthes falcataria trees attacked by Xystrocera festiva. The fungi were out isolated from both the bark and sapwood tissues in the stem in different stages of bore made by the insect and to find out the to X. festiva. Therefore fungi were also isolated from the different organs of the imago and larva. Acremonium sp. 1 was isolated from the tree bark. From the surface of sapwood Trichoderma virens and Acremonium $s p$. (aff. Acremonium sp. st. imperfect Nectria arenuloides) there isolated. Trichoderma harzianum and Acremonium sp. (aff. Acremonium sp.st. imperfect $N$. cyathea) were found in discolored sapwood surrounding the insect tunnel. Acremonium spp. were also found from imago and larva of the insect. Therefore, there might be some form of interactions between Acremonium spp and X. festiva. There is an indication that T. virens and T. harzianum suppressed the development of Acremonium spp. in the stem of P. falcataria trees.
\end{abstract}

Key words: Acremonium, fungi, Paraserianthes falcataria, Trichoderma, Xystrocera festiva

\begin{abstract}
ABSTRAK
Penelitian ini bertujuan untuk mengetahui jenis-jenis fungi yang berkembang pada batang pohon Paraserianthes falcataria yang diserang oleh Xystrocera festiva. Fungi diisolasi dari kulit dan kayu gubal pada beberapa tahap gerekan X. festiva. Acremonium sp. 1 berhasil diisolasi dari kulit batang. Pada permukaan kayu gubal ditemukan Trichoderma virens dan Acremonium sp. (aff. Acremonium sp. st. imperfect Nectria arenuloides). Trichoderma harzianum dan Acremonium sp. (aff. Acremonium sp. st. imperfect $N$. cyathea) ditemukan pada terowongan kayu gubal yang dibuat oleh $X$. festiva. Acremonium spp. juga terdapat pada larva dan imago $X$. festiva. Hal ini menunjukkan adanya interaksi antara Acremonium spp. dengan $X$. festiva. Terdapat indikasi bahwa $T$. virens dan $T$. harzianum menekan perkembangan Acremonium spp. pada batang pohon P. Falcataria.
\end{abstract}

Kata kunci: Acremonium, fungi, Paraserianthes falcataria, Trichoderma, Xystrocera festiva

\section{PENDAHULUAN}




\section{A. Latar Belakang}

Pembangunan Hutan Tanaman Industri (HTI) merupakan kegiatan yang harus dilakukan untuk mengantisipasi akan kebutuhan dan kecukupan sumber bahan mentah bagi industri kayu di Indonesia. Pembangunan HTI dapat dijadikan sarana untuk mengurangi tekanan terhadap keberadaan hutan produksi alam yang mengandung spesies-spesies pohon berharga sehingga perlu dijaga kelestariannya.

Mengingat pentingnya peran HTI maka pemerintah dalam hal ini Departemen Kehutanan telah mencanangkan program untuk melakukan pembangunan HTI seluas 6.2 juta ha sampai tahun 2000 (Departemen Kehutanan, 1990). Tegakan HTI terdiri atas jumlah spesies yang terbatas dan kadangkala berbentuk monokultur (Sulthoni, 1986). Menurut Metcalf dan Luckman (1982), ekosistem monokultur lebih rentan terhadap serangan hama dan penyakit, karena keanekaragaman spesies tanaman rendah dan terjadi perubahan kondisi lingkungan yang disebabkan oleh manusia.

Spesies-spesies pohon hutan yang akan digunakan untuk pembangunan HTI merupakan informasi yang penting untuk penelaahan masalah gangguan yang akan dihadapi, terutama gangguan yang disebabkan oleh hama dan penyaki (Sulthoni,1986). Paraserianthes falcataria merupakan satu diantara beberapa spesies pohon yang ditetapkan untuk dianjurkan ditanam dalam pembangunan HTI. Menurut Soerinegara (1986) spesies ini memiliki beberapa keunggulan antara lain pertumbuhannya yang cepat dan mampu bersaing dengan gulma sehingga dapat cepat menutupi tanah. Menurut Hasan dkk. (1990), selain digunakan untuk pembangunan HTI, spesies pohon ini juga digunakan untuk kegiatan agroforestry, program penghijauan dan reboisasi yang dikenal dengan sengonisasi.

Masalah yang paling umum dihadapi dalam pengusahaan $P$. falcataria sampai saat ini adalah serangan hama penggerek batang Xystrocera festiva yang dikenal dengan nama boktor, uter-uter atau wowolan (Suharti dan Hardi, 1992). Pada tahun 1960-an X. festiva ini telah menghancurkan pertanaman P. falcataria di Pulau Jawa. Hama ini merupakan penggerek batang yang masih sulit dikendalikan (Suratmo, 1994).

Borror dkk. (1989) menyatakan, adanya serangan serangga penggerek kayu membuat terowonganterowongan yang dapat merupakan jalan pintu masuk bagi fungi dan organisme pelapuk kayu dan dapat memperlemah tumbuhan atau jaringan kayu hingga batang pohon mudah patah. Menurut Hadi (1994) gangguan terhadap pohon dapat menjadi lebih berat karena adanya asosiasi antara patogen dan serangga.

Spesies fungi yang berada pada bekas gerekan X. festiva pada batang pohon P. falcataria belum diketahui. Apakah $X$. festiva berperan dalam penyebaran spesies-spesies fungi yang terdapat pada batang pohon yang digereknya, itupun belum diketahui. Informasi ini diperlukan untuk mengetahui apakah spesies-spesies fungi yang berkembang dalam jaringan kayu batang, merupakan spesies-spesies fungi pelapuk kayu.

\section{B. Tujuan Penelitian}

Penelitian ini bertujuan untuk (1) mengetahui spesies fungi yang terdapat pada bagian batang pohon $P$. falcataria yang terserang $X$. festiva pada beberapa tahap penggerekan kayu; (2) mengetahui keterkaitan X. festiva dan fungi pada bagian jaringan kayu batang pohon $P$. falcataria.

\section{Hipotesis Penelitian}

(1) Terdapat spesies-spesies fungi tertentu pada jaringan kayu yang mengalami beberapa tahap gerekan X. festiva pada batang pohon P. falcataria; (2) Fungi yang terdapat pada beberapa tahap gerekan $X$. festiva pada batang pohon P. falcataria, dapat dijumpai pada berbagai bagian tubuh $X$. festiva.

\section{BAHAN DAN METODE}

\section{A. Tempat dan Waktu Penelitian}

Penelitian ini dilakukan di Laboratorium Divisi Mikrobiologi, Laboratorium Kimia, Institut Pertanian Bogor. Penelitian dilakukan pada bulan Agustus 1997 sampai dengan bulan Januari 1998.

\section{B. Metode Penelitian}


Penelitian dilakukan dengan tahapan sebagai berikut : (1) Penentuan kriteria sampel; (2) Pengambilan sampel; (3) Isolasi fungi dari batang pohon $P$. falcataria yang digerek $X$. festiva; (4) Isolasi fungi dari berbagai bagian tubuh $X$. festiva; (5) Identifikasi fungi yang diisolasi, dan (6) Interaksi fungi dengan $X$. festiva.

\section{Penentuan kriteria sampel}

Pohon $P$. falcataria yang digunakan pada penelitian ini berumur 3 - 4 tahun, yang tumbuh pada kebun rakyat di Cibedug, Bogor. Sampel dibagi dalam tiga kelompok tahap gerekan, yaitu kulit, permukaan kayu gubal, dan terowongan kayu gubal. Sampel yang digunakan untuk isolasi fungi diambil dari tiga pohon.

\section{Pengambilan sampel}

Batang pohon yang telah ditentukan tahap gerekannya tersebut ditebang. Pengambilan sampel untuk isolasi fungi dilakukan dengan cara : Pemotongan bagian batang pohon yang digerek yaitu : (a) kulit batang; (b) permukaan kayu gubal, dan (c) pemotongan bagian terowongan dalam kayu gubal.

Untuk menentukan suatu gerekan batang pohon oleh X. festiva itu lama, pertengahan (antara lama dan baru) atau baru digerek digunakan kriteria perubahan warna pada bagian kayu dalam batang yang terserang. Pada bagian yang sudah lama digerek, bagian kayu batang terlihat berwarna coklat kehitaman. Pada bagian yang baru digerek, warna kayu sama dengan kayu gubal yang tidak terserang yaitu berwarna putih kekuningan. Bagian pertengahan digerek kayu terlihat berwarna coklat muda. Cara lain dalam penentuan kriteria adalah dengan melihat pola serangan $X$. festiva, dari yang lama sampai yang baru digerek, yaitu dari bawah ke arah atas pada batang pohon $P$. falcataria, baik pada permukaan kayu gubal maupun bagian terowongan kayu gubal.

\section{Isolasi fungi dari batang pohon $P$. falcataria yang terserang $X$. festiva}

Isolasi dilakukan dengan cara memotong bagian kayu menggunakan pisau steril sehingga diperoleh potongan-potongan dengan ukuran $5 \times 5 \times 2 \mathrm{~mm}$. Potongan-potongan tersebut direndam selama 1 - 3 menit dalam larutan chlorox 1\% untuk sterilisasi permukaan. Potongan-potongan ini selanjutnya dibilas dengan air steril, serta selanjutnya dikeringanginkan dengan menempatkannya pada permukaan kertas steril sebanyak 3 potong untuk tiap kriteria sampel yang telah dikeringanginkan kemudian ditanam pada media Malt Extract Agar (MEA). Ada tujuh perlakuan isolasi yang dilakukan, yaitu A = Isolasi fungi dari bagian kulit yang digerek, $\mathrm{B}_{1}=$ Isolasi fungi dari bagian permukaan kayu gubal yang sudah lama digerek, $\mathrm{B}_{2}=$ Isolasi fungi dari bagian permukaan kayu gubal pertengahan digerek, $\mathrm{B}_{3}=$ Isolasi fungi dari permukaan kayu gubal yang baru digerek, $\mathrm{C}_{\mathrm{I}}=$ Isolasi fungi dari bagian terowongan kayu gubal yang sudah lama digerek, $\mathrm{C}_{2}=$ Isolasi fungi dari bagian terowongan kayu gubal pertengahan digerek dan $\mathrm{C}_{3}=$ Isolasi fungi dari bagian terowongan kayu gubal yang baru digerek. Media MEA yang telah berisi potongan-potongan kayu diinkubasi pada suhu ruang selama 5 sampai 7 hari.

\section{Isolasi fungi dari berbagai bagian tubuh $X$. festiva}

Isolasi dilakukan dari bagian tubuh larva instar akhir dan dari bagian tubuh imago X. festiva. Fungi diisolasi dari permukaan tubuh dan esofagus larva instar akhir. Untuk imago, fungi diisolasi dari beberapa bagian tubuh imago, yaitu antena, kepala, thoraks, abdomen, tungkai dan sayap. Bagian-bagian tubuh ditanam pada media MEA, selanjutnya diinkubasi selama 5 sampai 7 hari pada suhu ruang. Proses isolasi bagian tubuh larva dan tubuh imago $X$. festiva dilakukan sama dengan proses isolasi fungi dari batang $P$. falcataria.

\section{Identifikasi}

Pemurnian isolat fungi dilakukan dengan membiakkan secara berulang-ulang (sub-culture) pada media MEA. Biakan diinkubasi selama 5 - 7 hari pada suhu ruang. Setelah mendapatkan isolat murni maka dilakukan pengamatan secara makroskopis. Parameter-parameter makroskopis yang diamati adalah sifat tumbuh hifa, warna koloni dan warna massa konidia. Pengamatan mikroskopis dilakukan dengan cara membuat kultur fungi pada gelas obyek (slide culture). Potongan media agar sebesar 4 × 4 x 2 mm yang 
telah ditumbuh fungi diletakkan pada kaca obyek, kemudian ditutup dengan kaca penutup. Kultur kaca obyek ini diinkubasi dalam kotak plastik berukuran $30 \times 20 \times 6 \mathrm{~cm}$, selama 5 - 7 hari dalam kondisi lembab. Setelah fungi tumbuh dan berkembang pada kaca obyek dan kaca penutup, dilakukan pembuangan potongan agar. Kaca penutup yang ditumbuhi fungi ditempatkan kembali tepat di atas kaca obyek yang juga ditumbuhi fungi. Fungi pada kaca obyek diamati ciri mikroskopiknya yaitu ciri-ciri hifa, ada tidaknya sekat pada hifa, tipe percabangan hifa, konidiogenesis, serta ciri-ciri konidium (bentuk dan rangkaian). Ciri-ciri yang diperoleh ditabulasi, kemudian dicocokkan dengan kunci identifikasi yang dikemukakan oleh Samuels (1976) dan Bisset (1991).

\section{HASIL DAN PEMBAHASAN}

\section{a. Hasil}

\section{Fungi dari batang pohon $P$. falcataria yang terserang $X$. festiva}

Hasil isolasi fungi dari kulit, lubang gerek dan batang $P$. falcataria diperoleh tujuh isolat fungi. Fungi-fungi ini dikelompokkan ke dalam dua genus yaitu Acremonium dan Trichoderma. Spesies fungi yang diperoleh dapat dilihat pada Tabel 1.

Tabel(Table) 1. Fungi dari batang pohon P. falcataria yang terserang X. festiva (Fungi isolated from the stem of $\mathrm{P}$. falcataria tree attacked by X. festiva)

\begin{tabular}{|c|c|c|c|}
\hline \multirow{2}{*}{$\begin{array}{c}\text { Bagian batang } \\
\text { (Part of tree's stem) }\end{array}$} & \multicolumn{3}{|c|}{ Tahap gerekan (Phase of attack) } \\
\hline & $\begin{array}{l}\text { Lama } \\
(\text { Old })\end{array}$ & $\begin{array}{l}\text { Pertengahan } \\
\text { (Medium) }\end{array}$ & $\begin{array}{l}\text { Baru } \\
(\mathrm{New})\end{array}$ \\
\hline Kulit (Bark) & - & - & Acremonuim sp. 1 \\
\hline Permukaan kayu gubal & T. virens & T. virens & $\begin{array}{l}\text { Acremonium sp. (aff. } \\
\text { Acremonium sp. st. } \\
\text { imperfect Nectria } \\
\text { arenuloides) }\end{array}$ \\
\hline Terowongan kayu gubal & T. harzianum & T. harzianum & $\begin{array}{l}\text { Acremonium sp. (aff. } \\
\text { Acremonium sp. st. } \\
\text { imperfect } N \text {. cyathea) }\end{array}$ \\
\hline
\end{tabular}

Perbedaan antara spesies Trichoderma virens (Gambar 1) dan T. harzianum (Gambar 2) yang berasal dari batang pohon P. falcataria dapat dilihat pada Tabel 2 .


Gambar(Figure) 1. Trichoderma harzianum A. Bentuk koloni umur 14 hari pada suhu ruang B. Bentuk mikroskopik a. konidiofor, b. Fialid dan c. konidia (Trichoderma harzianum $A$. Form of colony 14 days old MEA media in room temperature B. Form of microscopic a. conidiophore b. phialide and C. conidia) 

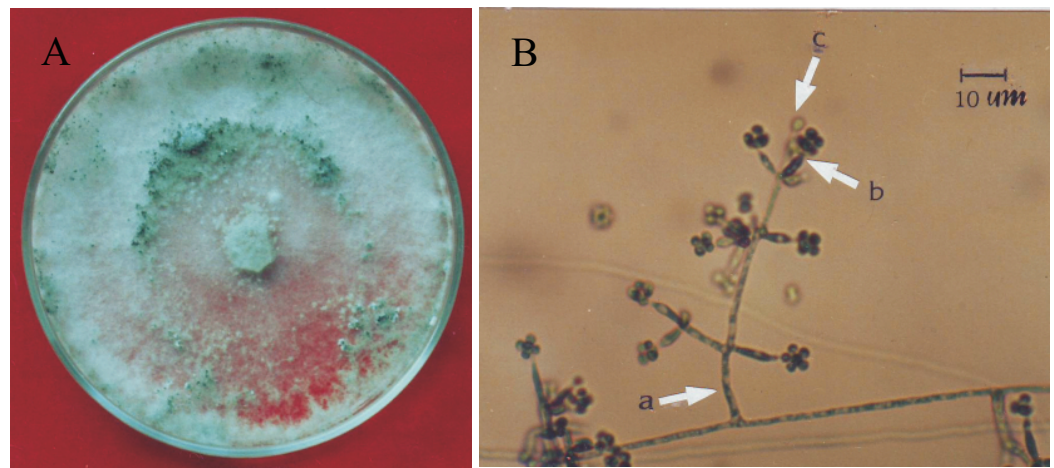

Gambar(Figure) 2. Trichoderma virens A. Bentuk koloni umur 14 hari pada suhu ruang B. Bentuk mikroskopik a. konidiofor, b. fialid dan c. Konidia (Trichoderma virens $A$. Form of colony at 14 days old MEA media in room temperature B. Form of microscopic a. conidiophore b. phialide and c. Conidia)

Tabel(Table) 2. Perbedaan karakteristik antara Trichoderma virens dan T. harzianum dari batang pohon $P$. falcataria (Characteristic differences between of Trichoderma virens and $\mathrm{T}$. harzianum isolated from stem of $\mathrm{P}$. falcataria)

\begin{tabular}{|l|l|l|l|l|}
\hline $\begin{array}{l}\text { Spesies fungi } \\
\text { (Fungi species) }\end{array}$ & $\begin{array}{c}\text { Warna koloni } \\
\text { Diameter } \\
\text { (Color of colony) }\end{array}$ & $\begin{array}{c}\text { Konidiofor } \\
\text { (Conidiovore) } \\
\text { (LD. LU) }\end{array}$ & $\begin{array}{c}\text { Fialid (Fialid) } \\
\text { (Bentuk, ukuran) } \\
\text { (Form, size) }\end{array}$ & $\begin{array}{l}\text { Konidia (Conidia) } \\
\text { (Bentuk, ukuran) } \\
\text { (Form, size })\end{array}$ \\
\hline T.virens & $\begin{array}{l}\text { Putih keabuan } \\
\text { pada awal, } \\
\text { bagian tengah } \\
\text { hijau pada } \\
\text { tahap lanjut } \\
7-9 \mathrm{~cm}, 4 \text { hari }\end{array}$ & $\begin{array}{l}5.0-6.9 \mu \mathrm{m} \\
3.5-5.0 \mu \mathrm{m}\end{array}$ & $\begin{array}{l}\text { Lageniform } \\
3.8-11.3 \times 2.8-4.5 \mu \mathrm{m}\end{array}$ & $\begin{array}{l}\text { Ellips lebar \& } \\
\text { obovoid } \\
2.5-5.0 \times 1.5-3.9 \mu \mathrm{m}\end{array}$ \\
\hline T. harzianum & $\begin{array}{l}\text { Putih keabuan } \\
\text { pada awal, } \\
\text { bagian tengah } \\
\text { hijau keputihan } \\
\text { pada tahap } \\
\text { lanjut } \\
7-9 \mathrm{~cm}, 4 \text { hari }\end{array}$ & $\begin{array}{l}5.0-7.0 \mu \mathrm{m} \\
2.5-3.8 \mu \mathrm{m}\end{array}$ & $\begin{array}{l}\text { Ampulliform dan } \\
\text { Lageniform } \\
3.5-7.5 \times 2.5-3.8 \mu \mathrm{m}\end{array}$ & $\begin{array}{l}\text { Globose, } \\
\text { subglobose, } \\
\text { obovoid } \\
2.5-3.8 \times 1.9-2.5 \mu \mathrm{m}\end{array}$ \\
\hline
\end{tabular}

Keterangan: LD = Lebar Dasar

\section{Fungi dari Berbagai Bagian Tubuh Imago dan Larva $X$. festiva}

Dari bagian tubuh serangga (imago dan larva) didapatkan tiga isolat fungi. Fungi yang diperoleh adalah genus Acremonium. Adapun spesies yang diperoleh pada berbagai bagian tubuh $X$. festiva dapat dilihat pada Tabel 3 . 
Tabel(Table) 3. Fungi dari berbagai bagian tubuh imago dan larva X. festiva (Fungi isolated from different organs of the imago and larvae of $\mathrm{X}$. festiva)

\begin{tabular}{|l|l|}
\hline \multicolumn{1}{|c|}{$\begin{array}{c}\text { Bagian tubuh X. festiva } \\
\text { (Part of X. festiva's body) }\end{array}$} & \multicolumn{1}{c|}{ Fungi yang diperoleh } \\
\hline Thoraks & Acremonium sp. 1 \\
Abdomen & Acremonium sp.1 \\
Tungkai & Acremonium sp.2 \\
Antena & - \\
Kepala & - \\
Sayap & Acremonium sp.3 \\
Permukaan tubuh larva & Acremonium sp.3 \\
Esofagus larva & Acremonium sp.3 \\
\hline
\end{tabular}

Perbedaan antara spesies Acremonium yang berasal dari batang P. falcataria (Gambar 3) dan Acremonium yang berasal dari bagian tubuh X. festiva (Gambar 4) dapat dilihat pada Tabel 4.
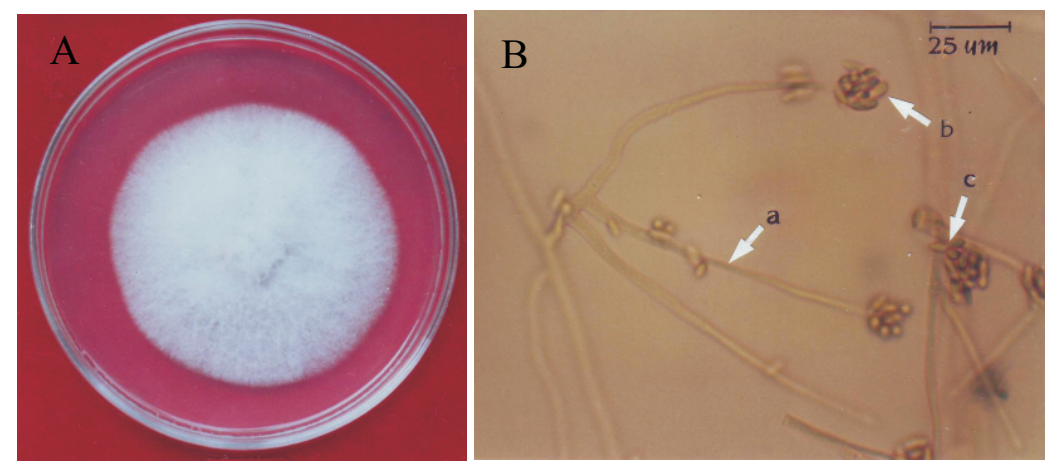

Gambar(Figure) 3. Acremonium sp. (aff. Acremonium sp. st. imperfect Nectria arenuloides) dari batang P. falcataria A. Bentuk koloni pada media MEA umur 14 hari pada suhu ruang B. Bentuk mikroskopik a. fialofor, b. kepala berlendir dan c. konidia (Acremonium sp. (aff. Acremonium sp. st. imperfect Nectria arenuloides) from the stem of $\mathrm{P}$. falcataria A. Form of colony at 14 days old MEA media in room temperature B. Form of microscopic a. Phialophore, b. slime heads and c. conidia)
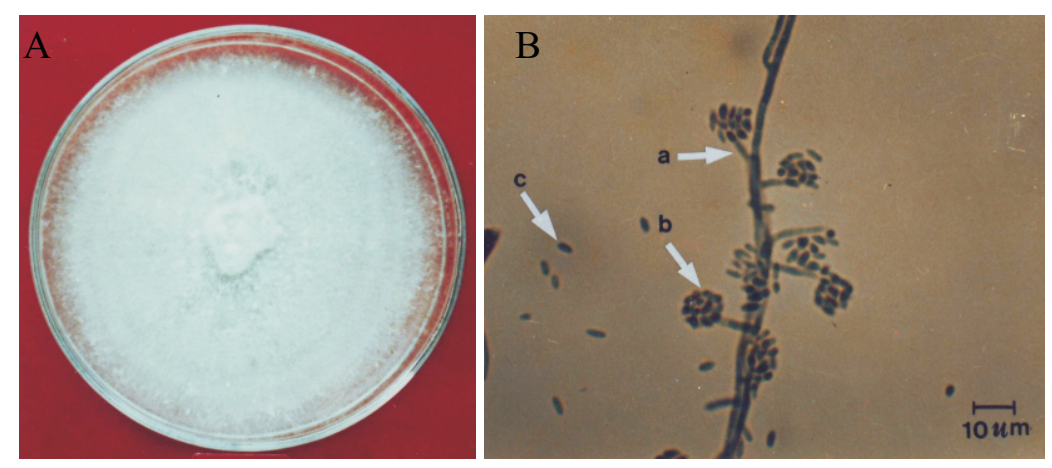

Gambar(Figure) 4. Acremonium sp. 1 dari imago dan larva X. festiva A. Bentuk koloni pada media MEA umur 14 hari pada suhu ruang B. Bentuk mikroskopik a. fialofor, b. kepala berlendir dan c. Konidia (Acremonium sp. 1 from the imago and larvae X. festiva A. Form of colony at 14 days old MEA media in room temperature B. Form of microscopic a. Phialophore, b. slime heads and c. conidia) 
Tabel(Table) 4. Perbedaan spesies Acremonium dari batang pohon P. falcataria dan bagian tubuh $X$. festiva (Characteristic differences among Acremonium species isolated from the stem of $\mathrm{P}$. falcataria and the organs of $\mathrm{X}$. festiva)

\begin{tabular}{|c|c|c|c|c|}
\hline $\begin{array}{l}\text { Spesies fungi } \\
\text { (Fungi species) }\end{array}$ & $\begin{array}{c}\text { Warna koloni } \\
\text { Diameter } \\
\text { (Color of colony) }\end{array}$ & $\begin{array}{c}\text { Fialofor } \\
\text { (Fialovore) } \\
\text { (P. LD. LU ) }\end{array}$ & $\begin{array}{c}\text { Konidia (Conidia) } \\
\text { (Bentuk, ukuran) } \\
(\text { Form, size }) \\
\end{array}$ & $\begin{array}{l}\text { Jumlah } \\
\text { Septa } \\
\text { (Total) } \\
\end{array}$ \\
\hline Acremonium sp.1 & $\begin{array}{l}\text { Putih keabuan } \\
7-9 \mathrm{~cm}, 14 \text { hari }\end{array}$ & $\begin{array}{l}5.0-140 \mu \mathrm{m} \\
1.0-3.8 \mu \mathrm{m} \\
0.6-2.5 \mu \mathrm{m}\end{array}$ & $\begin{array}{l}\text { Ellips, oblong \& } \\
\text { fusiform } \\
4.4-11.3 \times 1.4-3.8 \mu \mathrm{m}\end{array}$ & tanpa - 3 \\
\hline $\begin{array}{l}\text { Acremonium sp. } \\
\text { (aff. Acremonium } \\
\text { sp.st. imperfect } \\
\text { N. arenuloides ) }\end{array}$ & $\begin{array}{l}\text { Putih menye - } \\
\text { rupai kapas } \\
4-5 \mathrm{~cm}, 14 \text { hari }\end{array}$ & $\begin{array}{l}33-88 \mu \mathrm{m} \\
1.5-3.0 \mu \mathrm{tm} \\
1.0-1.5 \mu \mathrm{m}\end{array}$ & $\begin{array}{l}\text { Ellips, fusiform } \\
10-12.5 \times 2.5-3.8 \mu \mathrm{m}\end{array}$ & tanpa - 4 \\
\hline $\begin{array}{l}\text { Acremonium sp. } \\
\text { (aff. Acremonium } \\
\text { sp.st. imperfect } \\
\text { N. cyathea) }\end{array}$ & $\begin{array}{l}\text { Putih sampai } \\
\text { agak keku- } \\
\text { ning an trans - } \\
\text { paran } 4-5 \mathrm{~cm} \text {, } \\
14 \text { hari }\end{array}$ & $\begin{array}{l}70-110 \mu \mathrm{m} \\
2.5-3.8 \mu \mathrm{m} \\
1.9-2.4 \mu \mathrm{m}\end{array}$ & $\begin{array}{l}\text { Ellips mendekati } \\
\text { silindris } \\
7.5-15 \times 1.3-5.0 \mu \mathrm{m}\end{array}$ & $1-3$ \\
\hline Acremonium sp.2 & $\begin{array}{l}\text { Keputihan -krem } \\
6-7 \mathrm{~cm}, 14 \text { hari }\end{array}$ & $\begin{array}{l}62-75 \mu \mathrm{m} \\
3.1-3.8 \mu \mathrm{m} \\
1.0 .1 .5 \mu \mathrm{m}\end{array}$ & $\begin{array}{l}\text { Ellips, oblong \& } \\
\text { fusiform } \\
5.3-15 \times 1.3-5.0 \mu \mathrm{m}\end{array}$ & tanpa-3 \\
\hline Acremonium sp.3 & $\begin{array}{l}\text { Putih-krem } \\
4-5 \mathrm{~cm}, 14 \text { hari }\end{array}$ & $\begin{array}{l}50-88 \mu \mathrm{m} \\
2.5-4.0 \mu \mathrm{m} \\
1.3-1.9 \mu \mathrm{m}\end{array}$ & $\begin{array}{l}\text { Ellips, oblong \& } \\
\text { fusiform } \\
5.0-10 \times 1.3-5.0 \mu \mathrm{m}\end{array}$ & tanpa-3 \\
\hline
\end{tabular}

Keterangan : P = Panjang, $\mathrm{LD}=$ Lebar Dasar LU = Lebar Ujung

\section{B. Pembahasan}

Acremonium sp.1 yang ditemukan pada kulit batang (Tabel 1) dapat dihubungkan dengan terjadinya luka pada kulit batang yang disebabkan oleh imago $X$. festiva ketika meletakkan telurnya. Hasil ini ditunjang dengan ditemukannya juga Acremonium sp.1 dari bagian thoraks dan abdomen imago (Tabel 3). Menurut Austwick (1957) yang diacu oleh Carter (1973), serangga dapat menyebarkan fungi dengan cara menginokulasikannya pada bagian luka yang dibuatnya. Salah satu bentuk luka yang dibuat serangga adalah luka ketika meletakkan telur. Pada jaringan kayu yang luka spora fungi berkecambah dan mempenetrasi jaringan kayu (Agrios, 1997). Adapun Beaver (1989) dan Jolivet (1998) mengemukakan bahwa beberapa serangga menjadikan fungi sebagai bahan makanannya dan serangga ini juga berperan dalam menyebarkan spora fungi tersebut pada pohon-pohon yang dihinggapinya. Selanjutnya Jeger dan Spence (2001) menyatakan bahwa dalam interaksi serangga dengan fungi, serangga dapat berperan sebagai vektor dalam penyebaran fungi.

Pada permukaan kayu gubal terlihat adanya dominansi T. virens di bagian yang sudah lama digerek dan bagian pertengahan yang digerek (Tabel 1). Pertumbuhan koloni T. virens sangat cepat dan pada umur 14 hari diameternya sudah mencapai 7 - $9 \mathrm{~cm}$ (Bisset, 1991). Berdasarkan kecepatan pertumbuhan ini, besar kemungkinan $T$. virens mempunyai kemampuan kompetisi yang kuat, sehingga koloni mendapatkan ruang untuk tumbuh lebih luas dalam waktu singkat. Menurut Wells (1988) Trichoderma merupakan kompetitor yang baik untuk mendapatkan ruang tumbuh dan nutrisi. Hal ini dibuktikan dengan keberadaannya yang berlimpah pada tanah pertanian dan tanah hutan alam di dunia. Pada penelitian ini mungkin Acremonium sp. (aff. Acremonium sp. st imperfect $N$. arenuloides) kalah bersaing dengan $T$. virens, sehingga tempat-tempat yang pada awalnya dihuni oleh Acremonium sp. (aff. Acremonium sp. st imperfect $N$. arenuloides) dimanfaatkan oleh $T$. virens. 
Pada bagian terowongan kayu gubal yang sudah lama dan bagian pertengahan digerek larva $X$. festiva didapatkan T. harzianum (Tabel 1). Pola suksesi fungi pada terowongan kayu gubal ini sama dengan pola pada permukaan kayu gubal. Berdasarkan hasil penelitian ini T. harzianum diameter koloninya mencapai 7 - $9 \mathrm{~cm}$ pada umur 4 hari. Disamping pertumbuhan yang cepat, $T$. harzianum juga memiliki kemampuan kompetisi yang kuat dalam mendapatkan ruang untuk tempat tumbuh. Menurut Wells (1988), selain memiliki kemampuan kompetisi yang kuat Trichoderma juga mempunyai sifat mikoparasitik dan menghasilkan senyawa antibiosis. Acremonium sp. (aff. Acremonium sp. st imperfect $N$. cyathea) yang pada tahap awal menempati bagian terowongan kayu gubal, dengan bertambah waktu tempatnya akan diambil alih oleh T. harzianum.

\section{KESIMPULAN}

1. Pada jaringan kayu batang pohon $P$. falcataria yang terserang $X$. festiva (a) pada bagian kulit ditemukan Acremonium sp.1; (b) pada permukaan kayu gubal, T. virens dan Acremonium sp. (aff. Acremonium sp.st. imperfect $N$. arenuloides serta (c) pada terowongan kayu gubal, T. harzianum dan Acremonium sp. (aff. Acremonium sp.st. imperfect N. cyathea).

2. Spesies fungi yang tumbuh pada kulit batang pohon $P$. falcataria sama dengan spesies fungi yang diperoleh dari permukaan dada dan abdomen imago X. festiva yaitu Acremonium sp. 1, dengan demikian X.festiva berasosiasi dengan Acremonium sp. 1.

\section{DAFTAR PUSTAKA}

Agrios, G. N. 1997. Plant Pathology. 4rd Ed. Academic Press, Inc. San Diego, New York.

Beaver, R. A. 1989. Insect-Fungus Relationship in the Bark Ambrosia Beetles. Hlm 121-143 dalam InsectFungus Interaction. N. M. Wilding, N. M. Collins, P. M. Hammond dan J. F. Webber (Peny.). Academic Press. London, San Diego, New York, Berkeley, Boston, Sydney, Toronto, Tokyo.

Bissett, J. 1991. A Revision of the Genus Trichoderma. II. Infrageneric Classification. Can. J. Bot. 69: 2357-2372.

Borror, D.J., C.A. Triplehorn dan N.F. Johnson. 1989. Pengenalan Pelajaran Serangga. Terjemahan. Universitas Gadjah Mada. Yogyakarta.

Carter, W. 1973. Insect in Relation to Plant Disease. Second Edition. John Wiley \& Sons. New York, London, Sydney, Toronto.

Departemen Kehutanan. 1990. Pemanfaatan Hutan secara Lestari. Departemen Kehutanan Republik Indonesia. Jakarta.

Hadi, S. 1994. Perkembangan dan Status Bidang Perlindungan Hutan terhadap Penyakit dan Implementasinya dalam Kegiatan Pengelolaan Hutan. Makalah disampaikan pada Forum Komunikasi Hasil Penelitian Bidang Kehutanan, Direktorat Jenderal Pendidikan Tinggi 3 - 6 Oktober 1994 Cisarua-Bogor. Bogor

Hasan A., D. K. Permana, T. S. Aminah, A. R. Sutiawan, dan Azisadi. 1990. Hama Xystrocera festiva Pascoe pada Pohon Sengon dan Alternatif Penanggulangannya. Hlm 102-115 dalam Prosiding Seminar Nasional Sengonisasi. Jurusan Manajemen Hutan Fakultas Kehutanan IPB Bogor.

Jeger, M. J dan N. J. Spence. 2001. Biotic Interactions in Plant-Pathogen Associations. CABI Publishing. Wallingford, New York.

Jolivet, P. 1998. Interrelationship between Insects and Plants. CRC Press. Boca Raton, Boston, London, New York, Washington, D.C.

Metcalf, R. L., dan W. H. Luckmann. 1982. Introduction to Insect Pest Management. John Wiley \& Sons. New York, Chichester, Brisbane, Toronto, Singapore. 
Patton, R,F. 1990. Diseases of Forest Trees, Him 169-194 dalam Introduction to Forest Science, 2" Edition. R.A. Young dan R.L. Giese (Peny.). John Wiley \& Sons. New York, Chichester, Brisbane, Toronto, Singapore.

Samuels, G.J. 1976. Perfect States of Acremonium the Genera Nectria, Actiniopsis, Ijuhya, Neohenningsia, Ophiodictyon, and Peristomialis. New Zealand Journal of Botany 14: 231-260.

Soerianegara, I. 1986. The Use of Legumes for Reforestation and Greening in Indonesia. Rimba Indonesia $20: 27-33$.

Suharti, M dan T. H.T. Waluyo. 1992. Teknik Pengenalan Hama Xystrocera festiva Pascoe dan Usaha Pengendaliannya. Pusat Penelitian dan Pengembangan Hutan. Bogor.

Sulthoni, A. 1986. Permasalahan Perlindungan Tanaman pada Hutan Tanaman Industri dan Kaitannya dengan Teknologi Maju. Dalam Prosiding Seminar Nasional Ancaman terhadap Hutan Tanaman Industri. R. S. Wirakusumah (Peny.) Fakultas Matematika dan Ilmu Pengetahuan Alam Universitas Indonesia dan Departemen Kehutanan. Jakarta.

Suratmo, F. G. 1994. Perkembangan Perusak Hutan Tanaman Industri. Makalah disampaikan pada Forum Komunikasi Hasil Penelitian Bidang Kehutanan yang diselenggarakan pada tgl 3 - 6 Oktober 1994 Cisarua-Bogor. Bogor.

Wells, H.D. 1988. Trichoderma as a Biocontrol Agent. Hlm 71-82 dalam Biocontrol of Plant Disease. Vol.1. K.G. Mukerji dan K.L. Garg (Peny.). CRC Press Inc. Boca Raton. Florida. 